\title{
Fluctuation Speed as a New Criterion to Evaluate the Efficiency of Intravitreal Anti-VEGF Drugs
}

\author{
Abdullah Kaya \\ Department of Ophthalmology, Anıttepe Military Dispensary, Ankara, Turkey
}

\section{Dear Editor}

I read the article by Zinkernagel et al. [1] entitled 'Fluctuations in pigment epithelial detachment and retinal fluid using a bimonthly treatment regimen with aflibercept for neovascular age-related macular degeneration' with great interest. The authors evaluated intraretinal and subretinal fluid fluctuations in patients treated with aflibercept. I congratulate the authors for this well-organized study and want to make some contributions.

There are some criteria used to assess the efficiency of anti-VEGF drugs and to identify treatment intervals. Best-corrected visual acuity and central retinal thickness are the most common ones. Based on these criteria, treatment intervals for ran- ibizumab and bevacizumab are advised to be monthly and those for aflibercept bimonthly [2,3]. I appreciate the evaluation of fluid fluctuations presented by the authors because the speed of fluid fluctuation negatively correlates with the need for retreatment. A higher fluctuation speed (FS) of an anti-VEGF drug indicates that the efficiency period of this drug is short, and thus treatment intervals should be short too. On the contrary, a lower FS shows the necessity for a longer treatment period. I suggest that besides best-corrected visual acuity and central retinal thickness, FS should be used more commonly in studies about anti-VEGF drugs.

\section{References}

1 Zinkernagel MS, Wolf S, Ebneter A: Fluctuations in pigment epithelial detachment and retinal fluid using a bimonthly treatment regimen with aflibercept for neovascular age-related macular degeneration. Ophthalmologica 2016;235:42-48.

2 Regillo CD, Brown DM, Abraham P, Yue H, Ianchulev T, Schneider S, Shams N: Randomized, double-masked, sham-controlled trial of ranibizumab for neovascular age-related macular degeneration: PIER study year 1 . Am J Ophthalmol 2008;145:239-248.

3 Schmidt-Erfurth U, Kaiser PK, KorobelnikJF, et al: Intravitreal aflibercept injection for neovascular age-related macular degeneration: ninety-six-week results of the VIEW studies. Ophthalmology 2014;121:193-201.

\section{KARGER}

(C) 2016 S. Karger AG, Basel

0030-3755/16/2354-0242\$39.50/0

E-Mail karger@karger.com

www.karger.com/oph
Abdullah Kaya

Department of Ophthalmology, Anıttepe Military Dispensary

Yücetepe Mah. Gençlik Cad. 88, Sok Çankaya-Ankara

TR-06280 Ankara (Turkey)

E-Mail abdullahkayamd@ gmail.com 